\title{
Metode FAST \& Framework PIECES : Analisis \& Desain Sistem Informasi Penjualan Berbasis Website
}

\author{
Warjiyono', Fandhilah', Amin Nur Rais ${ }^{3}$, Ahmad Ishaq ${ }^{4}$ \\ ${ }^{1}$ Prodi Sistem Informasi Akuntansi, Universitas Bina Sarana Informatika \\ 2,4Prodi Sistem Informasi, Universitas Bina Sarana Informatika \\ 3 Teknologi Komputer, Universitas Bina Sarana Informatika

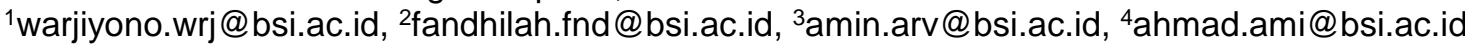

\begin{abstract}
The development of information and digital technology has accelerated the process of disruption in the business sector. Small business players are even able to beat big businesses because of innovation with digital technology. Internet users in Indonesia in 2018 totaled 171.17 million people, $93.9 \%$ used smartphones, $2.9 \%$ bought bags through online shops. Tas Murah Tegal is a physical shop that sells various types of bags and wallets. Currently, the way to market it is still through brochures, banners and social media. The problems that occur are difficulty controlling the amount of stock, sales data is often wrong, making sales reports that are often late and the difficulty in making reports for management purposes. The bag sales information system will be developed using the FAST method and the PIECES framework. Collecting data through interviews, observation and literature study. This information system is website-based using the programming language PHP, HTML, database using MySql. The purpose of this research is that Tas Murah Tegal can manage sales transactions more quickly, efficiently and effectively, data and information can be easily obtained and the availability of sales reports quickly. In addition, it can also expand market share, increase the number of sales, be able to compete globally, which is expected to grow and develop its business and improve good governance.
\end{abstract}

Keywords: FAST Method, Sales, PIECES, Information System

Abstrak: Perkembangan teknologi informasi dan digital mempercepat proses terjadinya disrupsi pada sektor bisnis. Pelaku bisnis kecil bahkan mampu mengalahkan bisnis besar karena inovasi dengan teknologi digital. Pengguna internet di Indonesia tahun 2018 berjumlah 171,17 juta jiwa, 93,9\% menggunakan smartphone, , 2,9\% nya membeli tas lewat toko online. Tas Murah Tegal merupakan toko fisik yang menjual beraneka macam jenis tas dan dompet. Saat ini cara memasarkannya masih melalui brosur, banner dan media sosial. Permasalahan yang terjadi kesulitan mengontrol jumlah stok, data-data penjualan sering salah, pembuatan laporan penjualan yang sering telat serta sulitnya membuat laporan-laporan untuk kepentingan manajemen. Sistem informasi penjualan tas akan dikembangakan dengan metode FAST dan framework PIECES. Pengumpulan data melalui wawancara, observasi dan studi pustaka. Sistem informasi ini berbasis website dengan menggunakan bahasa pemrograman PHP, HTML, database menggunakan MySql. Tujuan penelitian ini adalah agar Tas Murah Tegal dapat mengelola transaksi penjualan lebih cepat, efesien dan efektif, data dan informasi mudah didapatkan serta tersedianya laporan penjualan dengan cepat. Selain itu juga dapat memperluas pangsa pasar, meningkatkan jumlah penjualan, dapat bersaing secara global yang diharapkan dapat tumbuh dan berkembang bisnisnya dan meningkatkan tata kelola yang baik.

Kata kunci: Metode FAST, Penjualan, PIECES, Sistem Informasi

(7) (9) This is an open access article distributed under the Creative Commons Attribution License, which permits unrestricted use, distribution, and reproduction in any medium, provided the original work is properly cited. O2019 by author and IJSE-Indonesian Journal on Software Engineering.

\section{A. PENDAHULUAN}

Pengguna internet di Indonesia tahun 2018 berjumlah 171,17 juta jiwa, 93,9\% menggunakan smartphone (APJII, 2019). Perkembangan teknologi informasi dan digital mempercepat proses terjadinya disrupsi pada sektor bisnis. Pelaku bisnis kecil bahkan mampu mengalahkan bisnis 
besar karena inovasi dengan teknologi digital. Sektor bisnis khususnya perdagangan dituntut untuk beralih model bisnisnya dari yang berbasis toko konvensional menjadi toko online. Hal ini dilakukan untuk tetap bertahan dan bersaing di era industri 4.0 ini.. E-Commerce salah satu teknologi perdagangan online untuk memperluas pangsa pasar mempertemukan customer tanpa batas, dimanapun, kapanpun tanpa sekat tempat dan waktu.

Tas Murah Tegal merupakan sebuah toko konvensional yang menjual beraneka macam jenis tas dan dompet dengan model yang trendy dan mengikuti perkembangan fashion kekinian. Berdiri sejak tahun 2017, cara memasarkannya masih melalui brosur, banner dan media sosial. Perkembangan toko tidak begitu pesat karena banyak pesaing dari toko-toko yang ada saat ini. Jika strategi bisnis ini terus digunakan maka lambat laun akan kalah saingan karena jangkauan pasar masih sempit yang diprediksi dapat menurunkan pangsa pasar. Padahal dari 171,17 juta jiwa pengguna internet di Indonesia , 2,9\% nya membeli tas lewat toko online (APJII, 2019).

Permasalahan yang terjadi saat ini adalah kesulitan mengontrol jumlah stok, data-data penjualan sering salah, pembuatan laporan penjualan yang sering telat serta sulitnya membuat laporan-laporan untuk kepentingan manajemen dalam menentukan kebijakan dan strategi bisnisnya. Sistem informasi yang dikembangkan menggunakan metodologi FAST mampu membuat pengelolaan data dan informasi menjadi lebih efisien, efektif, akurat dan tepat waktu (Noorhansyah \& Pratomo, 2016). Sistem informasi dapat membantu proses pelayanan menjadi lebih cepat dan akurat serta proses pencatatan dan penyimpanan data dapat lebih baik, efesien waktu dan biaya (Rizan et al., 2018).

Penelitian yang pernah dilakukan sebelumnya oleh Halim berjudul "Sistem Informasi Penjualan Pada TB Harmonis Menggunakan Metode FAST" menggunakan 7 tahapan pengembangan sistem. Dengan adanya sistem informasi penjualan proses transaksi menjadi lebih cepat, efektif dan efisien, serta proses pembuatan laporan dapat dibuat lebih cepat. Selain itu dapat meningkatkan kinerja, efektifitas dan efisiensi perusahaan (Halim, 2020). Selain itu penelitian dilakukan oleh Irawan berjudul "perancangan sistem informasi penjualan pakaian pada CV. Nonninth Inc berbasis online" menggunakan analisis PIECES untuk menghimpun permasalahan dan kebutuhan sistem baru dengan memperhatikan faktor Performance, Information, Economic, Control, Efficiency dan Service (Irawan et al., 2017).

Untuk itu Tas Murah Tegal akan mengembangakan sistem informasi penjualan dengan menggunakan metode FAST dan framework PIECES. Sistem informasi ini berbasis website dengan menggunakan bahasa pemrograman PHP, HTML, database menggunakan MySql. Tujuan penelitian ini adalah agar Tas Murah Tegal dapat memperluas pangsa pasar, meningkatkan jumlah penjualan, dapat bersaing secara global yang diharapkan dapat tumbuh dan berkembang bisnisnya dan meningkatkan tata kelola yang baik.

\section{B. TINJAUAN PUSTAKA}

\section{FAST (Framework for the Application of System Thinking)}

Framework for the Application of System Thinking (FAST) merupakan metodologi pengembangan sistem berbentuk kerangka kerja. Metodologi FAST bagian dari agile modeling yang mendukung pengembangan sistem/aplikasi yang cepat, termasuk analisis sistem yang terstruktur, teknik informasi, dan analisis berorientasi objek dan desain (Muchsam, 2017).

FAST (Framework for the Applications of System Thinking) mendefinisikan tahapan untuk mengidentifikasi dan mengevaluasi permasalahan-permasalahan, kesempatan-kesempatan, hambatan-hambatan yang terjadi, dan kebutuhan yang diharapkan sehingga dapat diusulkan perbaikan-perbaikan (Noorhansyah \& Pratomo, 2016).

Metode FAST terdiri dari 8 (delapan) tahap (Stevens et al., 2018), yaitu tahap analisa dan desain (scope definition, problem analisis, requirements analysis dan logical design), tahap peralihan (decision analysis), tahap implementasi (physical design, construction \& testing, installation \& delivery).

Dapat disimpulkan bahwa Framework FAST merupakan metodologi pengembangan sistem yang mendukung untuk pengembangan aplikasi yang cepat dan dilakukan secara berurutan sesuai dengan tahapan-tahapan mulai dari tahap definisi lingkup, analisis masalah, analisis kebutuhan, desain logis, analisis keputusan, desain fisik \& integrasi, kontruksi \& pengujian, instalasi \& pengiriman. 


\section{PIECES}

PIECES (Performance, Information, Economic, Control, Efficiency and Service) merupakan model analisis yang digunakan untuk memperoleh pokok-pokok permasalahan yang lebih spesifik (Nurjamiyah \& Dewi, 2018). Analisis PIECES dilakukan saat akan memulai pengembangan sistem baru yaitu dengan menyusun beberapa masalah dari sistem lama kedalam kelompok aspek yaitu kinerja, informasi, ekonomi, pengendalian, efisiensi dan pelayanan untuk mendapatkan solusi pada sistem baru.

Analisis PIECES sangat penting untuk dilakukan sebelum tahapan pengembangan sistem dilakuka hal ini untuk menemukan permasalahan-permasalahan yang terjadi pada sistem lama, sehingga akan memudahkan pada saat menentukan kebutuhan-kebutuhan untuk sistem baru. Analisis PIECES dapat digunakan pada Framewotk FAST tahap awal yaitu definisi lingkup (scope definition).

\section{Sistem Informasi}

Sistem informasi merupakan sistem yang terdiri dari komponen perangkat lunak (software), perangkat keras (hardware), manusia (brainware) dan jaringan (network) untuk memproses data menjadi keluaran berupa informasi yang dibutuhkan perusahaan.

Sistem informasi memiliki peran yang sangat penting untuk menunjang manajemen dalam mendapatkan semua informasi yang akurat, cepat untuk memudahkan manajemen dalam mengambil keputusan strategis perusahaan (Warjiyono \& Faqih, 2019). Dengan sistem informasi maka perusahaan akan lebih meningkat produktifitasnya, efesiensi, memudahkan manajemen dalam perencanaan serta memudahkan pengelolaan transaksi perusahaan.

\section{Blackbox Testing}

Pengujian perangkat lunak adalah serangkaian proses menjalankan program dengan tujuan untuk menemukan kesalahan pada program tersebut. Selain itu melakukan pemeriksaan terperinci untuk mendapatkan hasil yang diharapkan sesuai fungsionalitas dari program tersebut. Proses menelusuri dan mempelajari sebuah program dalam rangka menemukan kesalahan pada perangkat lunak sebelum diserahkan kepada pengguna (Pressman, 2010).

Blackbox testing atau pengujian kotak hitam adalah metode pengujian perangkat lunak yang menguji fungsional (input dan output) dari masing-masing fitur pada software tanpa menguji kesalahan/error kode programnya. Pengujian dilakukan hanya fokus pada hasil eksekusi (masukan dan keluaran) melalui data uji dan memeriksa fungsionalitasnya tanpa mengetahui apa sesungguhnya yang terjadi pada logika kode programnya.

Pengujian blackbox memeriksa kesalahan interface, kesalahan dalam struktur data, kesalahan akses database dan fungsi-fungsi yang tidak benar.

\section{METODE PENELITIAN}

Metode penelitian sebagai berikut:

1. Pengumpulan data meliputi:

a. Observasi dilakukan untuk mengumpulkan data-data yang akan digunakan untuk sistem informasi penjualan tas yang akan dibangun seperti photo produk.

b. Wawancara dilakukan untuk mengetahui permasalahan-permasalahan yang terjadi pada sistem berjalan, kebutuhan-kebutuhan sistem sehingga akan mendapatkan gambaran dan solusi yang terbaik untuk mengatasi masalah tersebut.

c. Studi pustaka dilakukan untuk mendapatkan sumber-sumber literatur baik buku, internet, jurnal, proseding.

2. Metode pengembangan sistem menggunakan Framework for the Application of System Thinking (FAST). Ada 8 (delapan) tahap (Stevens et al., 2018), yaitu:

a. Tahapan Analisa \& Perancangan:

Tahap Analisa \& perancangan merupakan tahap awal dalam pengembangan sistem menggunakan metode FAST. Tahapan ini diantaranya: 
1) Definisi Lingkup yaitu tahap mengumpulkan informasi, permasalahan-permasalahan, kebutuhan-kebutuhan baru manajemen dan ruang lingkup proyek dengan menggunakan kerangka PIECES (Performance, Information, Economics, Control, Efficiency, Service).

2) Analisis Permasalahan yaitu tahap ini mengurai permasalahan sistem sebelumnya/berjalan.

3) Analisis Kebutuhan yaitu melakukan pengurutan prioritas dari kebutuhan-kebutuhan bisnis yang ada, diantaranya mengidentifikasi data, proses dan antarmuka yang diinginkan pengguna.

4) Desain Logis yaitu tahap mentransformasikan kebutuhan-kebutuhan bisnis untuk menggambarkan struktur data, bisnis proses, alur data, dan antar muka pengguna. Penggambaran bisa menggunakan symbol UML.

b. Tahapan Peralihan:

Tahapan peralihan merupakan tahapan ke dua dalam pengembangan sistem menggunakan metode FAST, yaitu:

5) Analisis Keputusan yaitu tahap untuk mempertimbangkan beberapa pilihan software dan hardware yang digunakan untuk mengimplementasikan sistem.

c. Tahapan Implementasi :

Tahapan implementasi merupakan tahapan ke tiga dalam pengembangan sistem menggunakan metode FAST, yaitu :

6) Desain Fisik yaitu tahap mentransformasikan kebutuhan bisnis kedalam desain fisik yang akan dijadikan sebagai acuan dalam membuat sistem yang akan dikembangkan.

7) Konstruksi \& Pengujian yaitu tahap untuk mengkonstruksi basisdata, program aplikasi, dan antarmuka untuk dilakukan pengujian terhadap sistem. Setelah uji coba sukses maka sistem siap diimplementasikan. Tahap ini banyak melibatkan sumber daya seperti SDM, waktu dan biaya.

8) Instalasi \& Pengiriman, yaitu tahap mengoperasikan sistem baru dan memberikan pelatihan kepada pengguna.

\section{HASIL DAN PEMBAHASAN}

Adapun tahapan analisa dan desain sistem informasi penjualan tas menggunakan metode FAST dan framework PIECES sebagai berikut:

1. Definisi Lingkup

Definisi lingkup berisi permasalah-permasalahan yang diklasifikasikan menggunakan analisis PIECES, seperti pada tabel1.

Tabel 1. Analisis PIECES

\begin{tabular}{|l|l|l|}
\hline No & Analisis & Sistem Saat Ini \\
\hline 1 & Performance (Kinerja) & Kecepatan untuk mendapatkan informasi lambat \\
\hline & & Pencarian data membutuhkan waktu lama \\
\hline & & Tenaga kerja terbatas \\
\hline 2 & Information (Informasi) & Informasi barang, harga dan stok sering tidak update \\
\hline & & Kebutuhan informasi manajemen tidak terpenuhi \\
\hline 3 & Economi (Ekonomi) & Biaya promosi dan komunikasi tinggi \\
\hline & & Biaya operasional tinggi seperti sewa toko, listrik, air, konsumsi \\
\hline 4 & Control (Pengendalian) & Biaya pembelian kertas, tinta tinggi \\
\hline & & Terjadi penumpukan berkas karena tata kelola yang buruk \\
\hline & & Sulit untuk mengontrol sumberdaya yang ada \\
\hline 5 & Efficiency (Efisiensi) & Sering terjadi barang, hilang dan tidak sesuai dengan stok \\
\hline & & Waktu yang diperlukan untuk proses transaksi lama \\
\hline 6 & Services (Layanan) & Pembuatan laporan membutuhkan waktu lama \\
\hline
\end{tabular}

Tabel 1 merupakan table yang menguraikan permasalahan-permasalahan yang terjadi pada system berjalan yang dikelompokan berdasarkan aspek kinerja, informasi, ekonomi, pengendalian, efisiensi dan layanan. Hasil uraian permasalahan tersebut berguna untuk mendapatkan solusi pada sistem baru yang akan dikembangkan.

2. Analisis permasalahan

Berdasarkan definisi lingkup yang telah dijabarkan pada table 1. maka selanjutnya menguraikan tiap-tiap permasalahan untuk mendapatkan gambaran solusinya.

Tabel 2. Analisis Permasalahan 


\begin{tabular}{|c|c|c|}
\hline Masalah & Penyebab & Solusi \\
\hline $\begin{array}{l}\text { Untuk mendapatkan informasi data } \\
\text { penjualan membutuhkan waktu } \\
\text { lama }\end{array}$ & $\begin{array}{l}\text { Sistem penjualan } \begin{array}{r}\text { manual } \\
\text { memperlambat } \\
\text { informasi }\end{array} \quad \text { mendapatkan } \\
\end{array}$ & $\begin{array}{l}\text { Sistem baru harus menyediakan menu informasi } \\
\text { pesanan, konfirmasi pembayaran dan } \\
\text { pengiriman }\end{array}$ \\
\hline $\begin{array}{l}\text { Pencarian data membutuhkan } \\
\text { waktu lama }\end{array}$ & $\begin{array}{l}\text { Pencarian data masih menggunakan } \\
\text { buku }\end{array}$ & $\begin{array}{l}\text { Sistem baru harus menyediakan fitur pencarian } \\
\text { yang baik }\end{array}$ \\
\hline $\begin{array}{l}\text { Informasi barang, harga dan stok } \\
\text { sering tidak update }\end{array}$ & $\begin{array}{l}\text { Sistem berjalan masih manual } \\
\text { berbasis buku }\end{array}$ & $\begin{array}{l}\text { Sistem baru harus mampu mengupdate informasi } \\
\text { barang, harga dan stok }\end{array}$ \\
\hline $\begin{array}{l}\text { Kebutuhan informasi manajemen } \\
\text { tidak terpenuhi }\end{array}$ & $\begin{array}{lcr}\text { Sistem lama } & \text { tidak } & \text { mampu } \\
\text { menyediakan } & \text { informasi } & \text { data } \\
\text { penjualan karena } & \text { masih manual }\end{array}$ & $\begin{array}{l}\text { Sistem baru harus menyediakan menu laporan } \\
\text { data penjualan yang spesifik per periodik, per } \\
\text { barang, per pelanggan agar kebutuhan informasi } \\
\text { manajemen terpenuhi }\end{array}$ \\
\hline Biaya pembelian kertas, tinta tinggi & 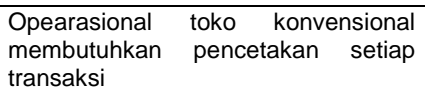 & $\begin{array}{l}\text { Sistem baru harus menyediakan fitur cetak atau } \\
\text { preview untuk bisa disimpan dalam bentuk } \\
\text { softcopy tanpa harus dicetak }\end{array}$ \\
\hline $\begin{array}{l}\text { Terjadi penumpukan berkas karena } \\
\text { tata kelola yang buruk }\end{array}$ & $\begin{array}{l}\text { Sistem lama masih bersifat berkas } \\
\text { fisik sehingga terjadi penumpukan }\end{array}$ & $\begin{array}{l}\text { Sistem baru harus paper less, semua dokumen } \\
\text { bisa disimpan dalam bentuk file }\end{array}$ \\
\hline $\begin{array}{l}\text { Sering terjadi barang, hilang dan } \\
\text { tidak sesuai dengan stok }\end{array}$ & $\begin{array}{l}\text { Sistem manual belum bisa } \\
\text { menyediakan data up to date }\end{array}$ & $\begin{array}{l}\text { Sistem baru harus menyediakan fitur } \\
\text { pengecekan stok berdasarkan data barang }\end{array}$ \\
\hline $\begin{array}{l}\text { Waktu yang diperlukan untuk } \\
\text { proses transaksi lama }\end{array}$ & $\begin{array}{l}\text { Sistem manual dari proses awal } \\
\text { pembelian hingga akhir dilakukan } \\
\text { dengan ,menulis }\end{array}$ & $\begin{array}{l}\text { Sistem baru haruis lebih cepat dan efesien } \\
\text { karena diproses oleh sistem }\end{array}$ \\
\hline $\begin{array}{l}\text { Pembuatan laporan membutuhkan } \\
\text { waktu lama }\end{array}$ & $\begin{array}{l}\text { Pembukuan di sistem lama masih } \\
\text { ditulis, dicari dari berbagai bukti } \\
\text { transaksi }\end{array}$ & $\begin{array}{l}\text { Sistem baru harus menyediakan laporan-laporan } \\
\text { penting yang diperlukan manajemen untuk } \\
\text { menentukan startegi bisnisnya }\end{array}$ \\
\hline $\begin{array}{l}\text { Layanan terhadap customer } \\
\text { menjadi terganggu dan lama }\end{array}$ & Keterbatasan dalam pelayanan & $\begin{array}{l}\text { Sistem baru harus mempercepat pelayanan } \\
\text { dengan menampilkan info kontak toko, } \\
\text { menyediakan fitur chat }\end{array}$ \\
\hline
\end{tabular}

Tabel 2 merupakan analisis permasalahan yang berisi penjabaran permasalahan, penyebab masalah dan solusinya. Solusi ini yang nantinya akan dibuat untuk pengembangan system baru.

3. Analisis kebutuhan

Analisa sistem informasi penjualan tas berikut ini, termasuk analisa kebutuhan fungsional, yaitu:

a. Analisis kebutuhan pengguna

Terdapat 3 pengguna yaitu owner, admin dan member

b. Analisis kebutuhan sistem

1) Menu beranda, kategori, kontak, profil, cara pesan, daftar User dan Login User serta laporan

2) Form pendaftaran untuk visitor menjadi member agar bisa pesan

3) Form Login untuk login user yang telah mendaftar

4) Form Pesan untuk pemesanan

5) Setiap barang ada deskripsi detail dan cara pesan

6) Form konfirmasi pembayaran

7) Form Login Admin.

8) Form produk, Form Kategori, Form Pelanggan, Form User.

9) Laporan penjualan

c. Analisis kebutuhan data

Adapun analisis kebutuhan data yang diperlukan dalam mengembangakan sistem informasi penjualan adalah:
1) Profil toko
2) Data pengguna
3) Data barang
4) Data pesanan
5) Data penjualan
6) Laporan

d. Analisis kebutuhan keamanan sistem

Adapun analisis kebutuhan keamanan system yang diperlukan dalam mengembangakan sistem informasi penjualan adalah:

1) Password login semua menggunakan enkripsi MD5, agar tidak diketahui oleh orang tidak punya hak akses. 
2) Maksimal jumlah kesalahan login sebanya 3 kali, jika lebih maka akan minta konfirmasi via email,

3) Beberapa interface hanya dapat diakses oleh pengguna tertentu sesuai kebutuhan pengguna.

4. Desain Logis

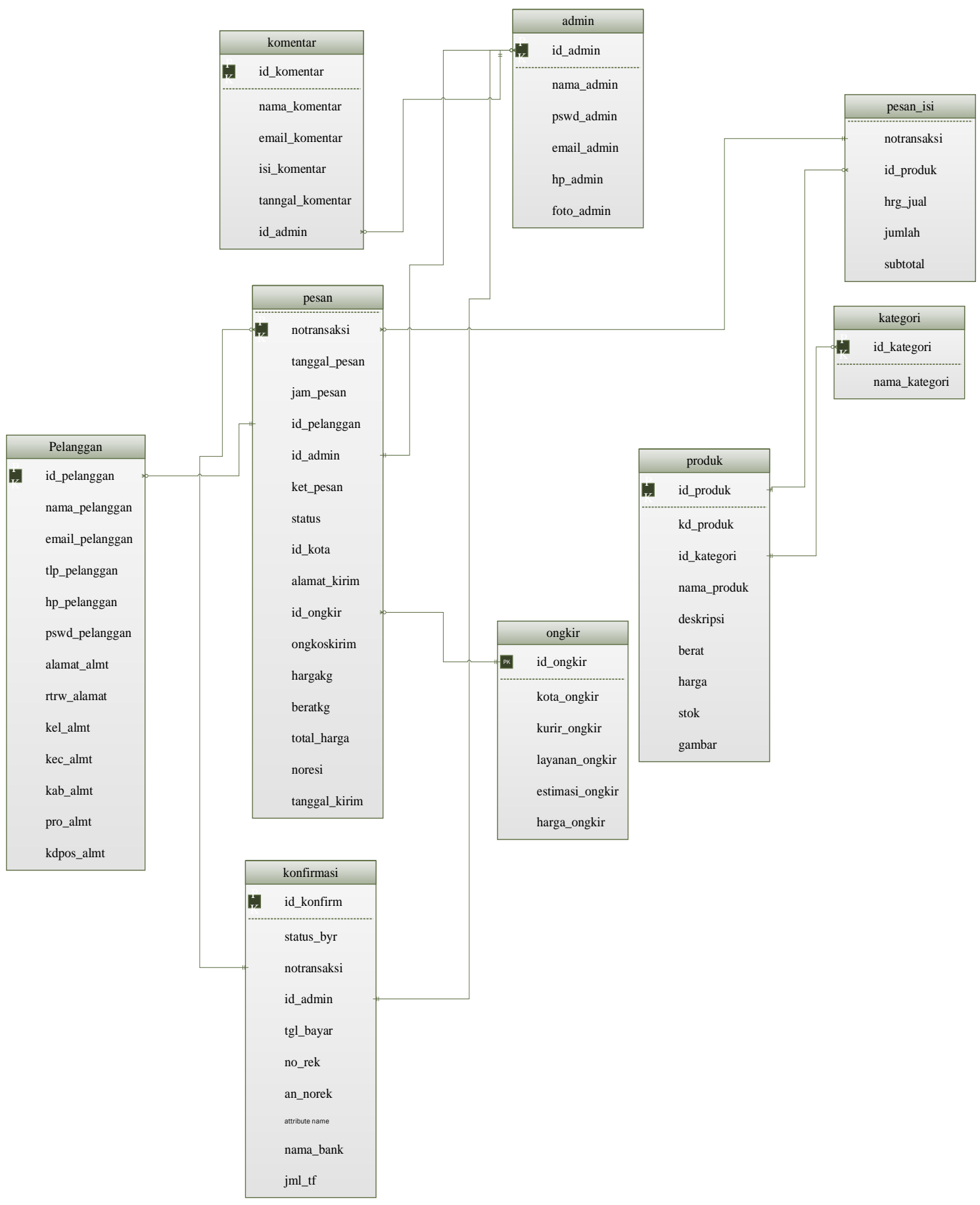

Gambar 1. Logical Record Structure

Gambar 1 merupakan Logical Record Structure yaitu rancangan dari table-tabel untuk merepresentasikan struktur record dari masing-masing tabel sekaligus menentukan kunci tamu atau Foreign Key (FK). 


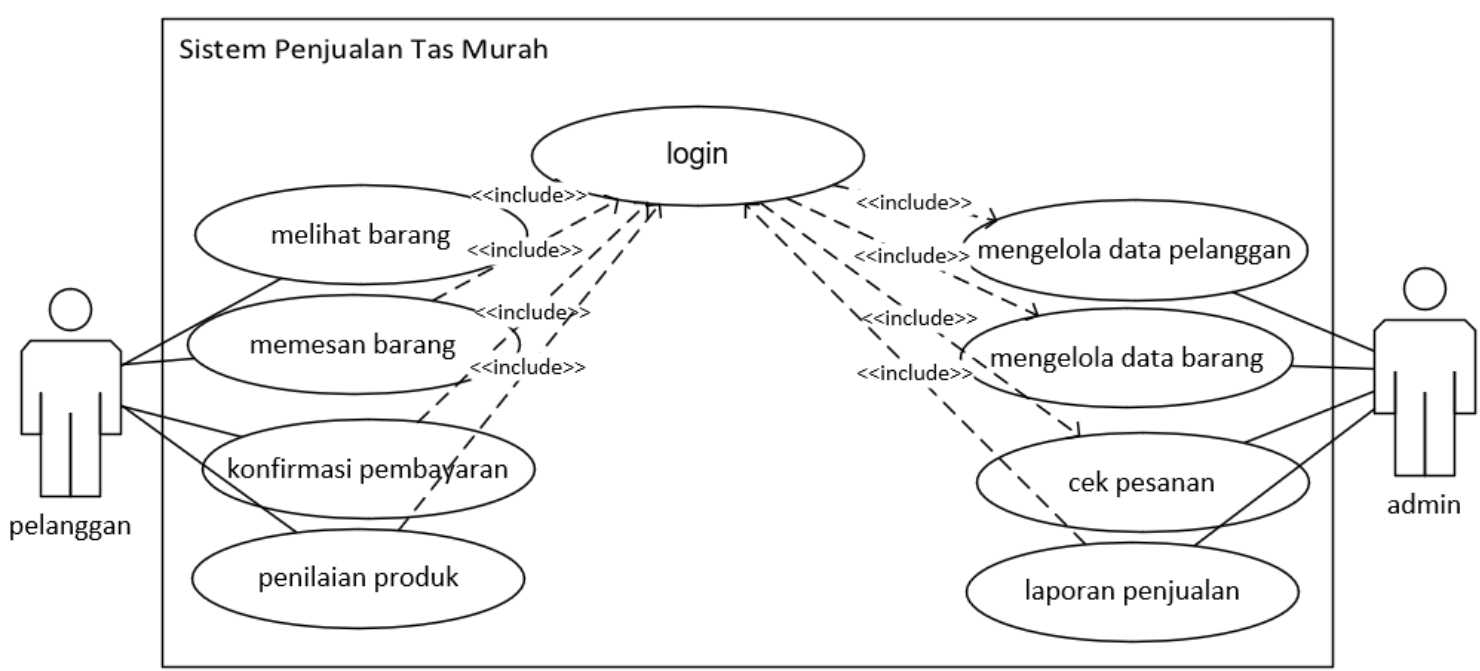

Gambar 2. Usecase Diagram

Gambar 2 merupakan usecase diagram yang menggambarkan interaksi pelanggan dan admin terhadap sistem. Pelanggan berinteraksi dengan sistem untuk login terlebih dahulu lalu dapat melihat barang, memesan barang, konfirmasi pembayaran dan penilaian produk. Begitupula dengan admin dapat berinteraksi dengan siistem login terlebih dahulu lalu dapat mengelola data pelanggan, mengelola stok/barang, cek pesanan dan laopran penjualan .

5. Analisis Keputusan

Analisis keputusan menentukan software dan hardware yang akan digunakan untuk mengimplementasikan sistem baru ini, yaitu:

a. Kebutuhan perangkat keras (hardware) yaitu 1 unit laptop/komputer, jaringan/koneksi internet dan printer

b. Kebutuhan perangkat lunak (software)

1) Sistem Operasi : Windows 10 Pro 64-bit

2) Web Server : Apache

3) Editor Web : Adobe Dreamweaver CC 2015

4) Database : MySQL

5) Web Browser : Mozilla Firefox, Google Chrome

6) Editor Foto : CorelDraw X7

6. Konstruksi

Konstruksi atau desain fisik yang sesungguhnya dibangun ada dua yaitu untuk back end dan front end. Tetapi tidak semua ditampilkan , hanya beberapa yang dijelaskan.

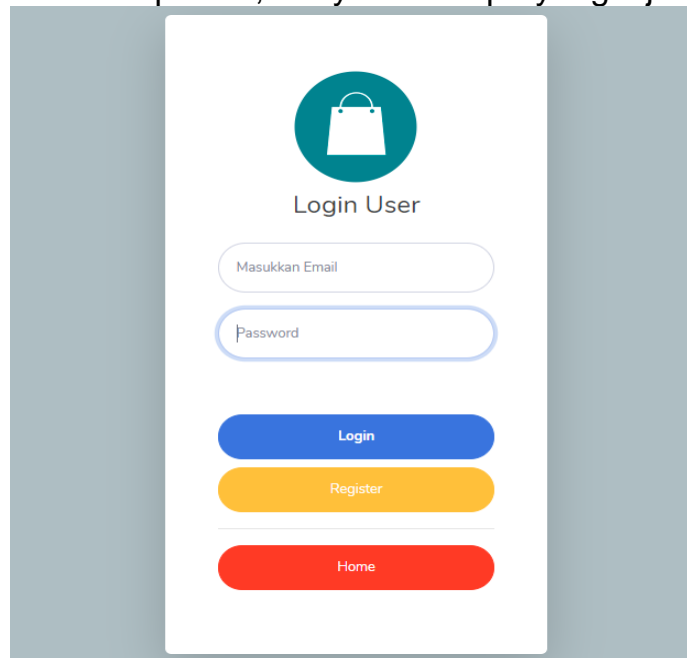




\section{Gambar 3. Antar muka login}

Gambar 3, merupakan tampilan antar muka login baik login untuk pengguna sebagai admin maupun pengguna sebagai pelanggan. Bagi pengguna baru maka harus melakukan pendaftaran salah satunya untuk menentukan useraname dan passwordnya dengan klik register sedangkan untuk yang sudah memiliki username dan password maka biasa langsung klik login.

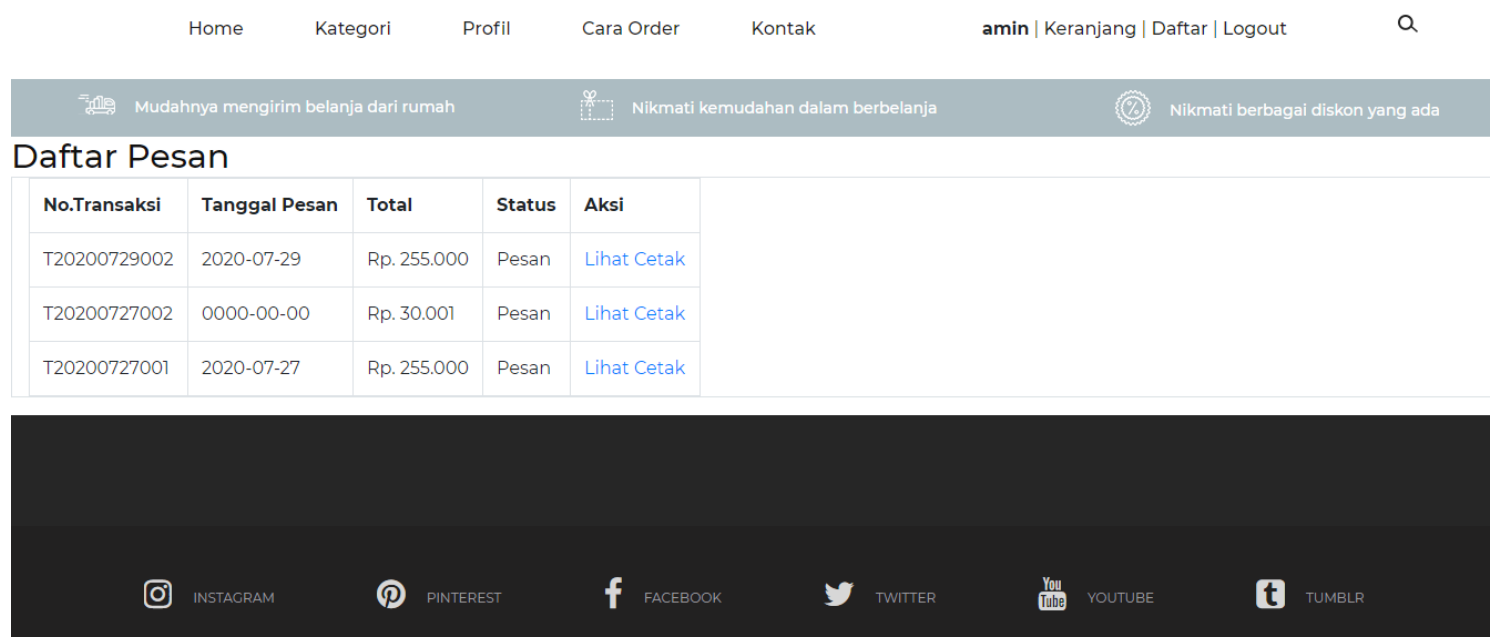

Gambar 4. Antar muka daftar pesanan

Gambar 4, merupakan tampilan antar muka daftar pesanan, untuk mempermudah pelanggan mendapatkan informasi data pesanan yang pernah dilakukan. Pelanggan juga dapat mencetak pesanan tersebut dengng klik menu lihat cetak.

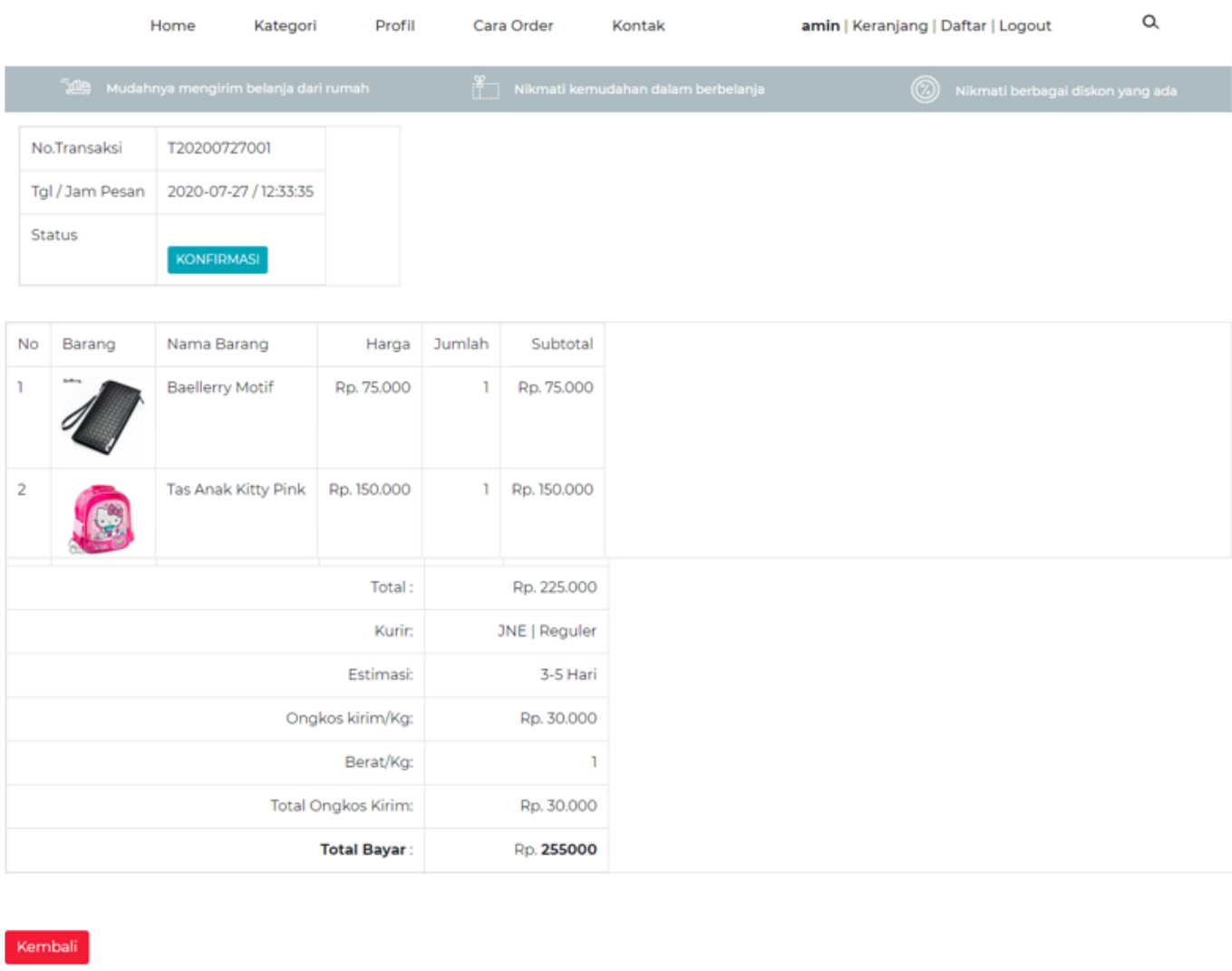


Gambar 5. Antar muka detail pengiriman

Gambar 5, merupakan antar muka detail informasi barang yang dibeli, informasi jasa pengiriman estimasi baranmg diterima, biaya pengitriman dan total yang harus dibayar yaitu total pembelian barang ditambah dengan biaya pengiriman.

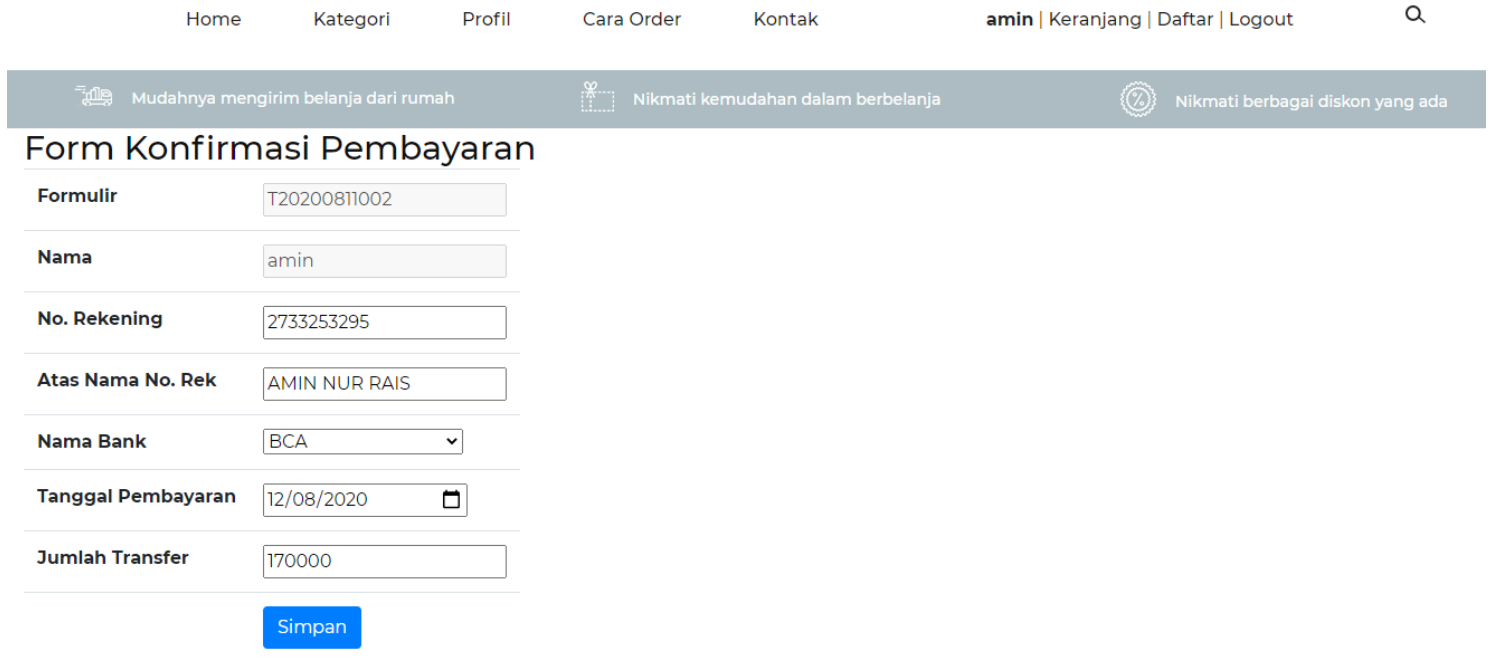

Gambar 6. Antar muka konfirmasi pembayaran

Gambar 6, merupakan antar muka pelanggan untuk mengkonfirmasi terkait pembayaran yang telah dilakukan melalui transfer bank. Data konfirmasi ini akan dilakukan pengecekan dan validasi oleh admin.

7. Pengujian

Pengujian telah dilakukan diseluruh interface yang ada. Dibawah ini ditampilkan salah satu pengujian untuk proses pemesanan menggunakan blackbox testing.

Tabel 3. Hasil Pengujian Antarmuka Pemesanan

\begin{tabular}{|c|c|c|c|c|c|}
\hline No & Skenario Pengujian & Test Case & Hasil yang diharapkan & $\begin{array}{c}\text { Hasil } \\
\text { Pengujian }\end{array}$ & Kesimpulan \\
\hline 1. & $\begin{array}{l}\text { Pengunjung melakukan } \\
\text { pemesanan tetapi tidak } \\
\text { melakukan login user } \\
\text { terlebih dahulu }\end{array}$ & $\begin{array}{l}\text { Pengunjung: menekan } \\
\text { tombol beli pada } \\
\text { produk tetapi belum } \\
\text { mendaftar sebagai user }\end{array}$ & $\begin{array}{l}\text { Sistem akan menolak } \\
\text { akses dan akan } \\
\text { menampilkan pop up } \\
\text { "Anda harus login" }\end{array}$ & $\begin{array}{l}\text { Sesuai } \\
\text { Harapan }\end{array}$ & Valid \\
\hline 2. & $\begin{array}{l}\text { Pengunjung sudah } \\
\text { melakukan registrasi } \\
\text { menjadi user tetapi tidak } \\
\text { melakukan login user } \\
\text { terlebih dahulu }\end{array}$ & $\begin{array}{l}\text { Pengunjung: menekan } \\
\text { tombol beli pada } \\
\text { produk tetapi sudah } \\
\text { mendaftar sebagai user }\end{array}$ & $\begin{array}{l}\text { Sistem akan menolak } \\
\text { akses dan akan } \\
\text { menampilkan pop up } \\
\text { "Anda harus login" }\end{array}$ & $\begin{array}{l}\text { Sesuai } \\
\text { Harapan }\end{array}$ & Valid \\
\hline 3. & $\begin{array}{l}\text { Pengunjung telah } \\
\text { melakukan login user } \\
\text { dengan benar }\end{array}$ & $\begin{array}{l}\text { Pengunjung: login } \\
\text { terlebih dahulu } \\
\text { kemudian menekan } \\
\text { tombol beli pada } \\
\text { produk }\end{array}$ & $\begin{array}{l}\text { Sistem akan menerima } \\
\text { akses dan kemudian } \\
\text { menampilkan halaman } \\
\text { keranjang belanja }\end{array}$ & $\begin{array}{l}\text { Sesuai } \\
\text { Harapan }\end{array}$ & Valid \\
\hline
\end{tabular}

\section{E. KESIMPULAN}

Sistem informasi penjualan Tas Murah Tegal berbasis website telah dikembangkan sistem baru menggunakan metode FAST \& framework PIECES sebagai pengganti sistem manual. Pengembangan sistem ini untuk mengatasi permasalahan yang terjadi seperti kesulitan mengontrol jumlah stok, data-data penjualan sering salah, pencarian data yang lama, pembuatan laporan penjualan yang sering telat serta sulitnya membuat laporan-laporan untuk kepentingan manajemen. Dengan adanya sistem baru maka Tas Murah Tegal dapat mengelola transaksi 
penjualan lebih cepat, efesien dan efektif, data dan informasi mudah didapatkan serta tersedianya laporan penjualan dengan cepat.

Sistem informasi penjualan Tas Murah Tegal berbasis website ini akan memperluas pangsa pasar, yang diharapkan dapat meningkatkan jumlah penjualan, dapat bersaing secara global yang diharapkan dapat tumbuh dan berkembang bisnisnya dan meningkatkan tata kelola yang baik.

Untuk kedepannya sistem informasi penjualan ini perlu dievaluasi kualitasnya agar diketahui kekurangan apa saja yang ada sehingga kekurangan tersebut akan menjadi prioritas untuk perbaikan di pengembangan sistem berikutnya.

\section{REFERENSI}

APJII. (2019). Penetrasi \& Profil Perilaku Pengguna Internet Indonesia Tahun 2018. In Apjii (p. 51). www.apjii.or.id

Halim, R. M. N. (2020). Sistem Informasi Penjualan Pada TB Harmonis Menggunakan Metode FAST. Jurnal Sisfokom (Sistem Informasi Dan Komputer), 9(2), 203-207. https://doi.org/10.32736/sisfokom.v9i2.868

Irawan, A., Risa, M., Ayyasy, M., \& Elyas, A. (2017). Perancangan Sistem Informasi Penjualan Pakaian Pada CV. Nonninth Inc Berbasis Online. Jurnal Positif, 3(2), 74-82. https://ejurnal.poliban.ac.id/index.php/Positif/article/view/417book_id=13629\&page=108\&c hkhashk=03C706812F\&ltemid=218\&lang=fa\&tmpl=component

Muchsam, Y. (2017). Pengembangan Sistem Informasi Kerawanan Pangan Berbasis SMS Gateway Dengan Menggunakan Metode FAST (Framework for the Applications of System Thinking) (Studi Kasus di Dinas Pangan Kabupaten Karawang ). Jurnal E-Komtek, 1(1), 99111.

Noorhansyah, M., \& Pratomo, A. (2016). Penerapan Model Customer Relationship Management Pada Metodologi FAST ( Studi Kasus: Pengembangan Portal Akademik Jurusan Administrasi Bisnis Politeknik Negeri Banjarmasin ). Jurnal POSITIF, I(2), 25-32.

Nurjamiyah, \& Dewi, A. R. (2018). Analisis Sistem Informasi Pengolahan Data Nilai Mahasiswa Menggunakan PIECES pada Prodi Sistem Informasi. Query, 5341(October), 37-46.

Pressman, R. S. (2010). Rekayasa Perangkat Lunak (Dhewiberta Hardjono (ed.); Edisi 7). Andi Yogyakarta.

Rizan, O., Hamidah, \& Pramana, D. (2018). Penerapan Metode FAST (Framework Application System Thinking) Untuk Peningkatan Pelayanan Air Bersih Kapal Sandar. Konferensi Nasional Sistem Informasi, 1036-1041.

Stevens, N. J., Salmon, P. M., Walker, G. H., Stanton, N. A., Stevens, N. J., Salmon, P. M., Walker, G. H., \& Stanton, N. A. (2018). Systems Analysis and Design Methods. In Human Factors in Land Use Planning and Urban Design. https://doi.org/10.1201/978131558736310

Warjiyono, \& Faqih, H. (2019). Analisa dan Perancangan Sistem Informasi Akuntansi : Desain dan Implementasi (Pertama). Graha Ilmu. 